・论坛・ 中国国家公园试点专题

\title{
东北虎豹国家公园试点经验
}

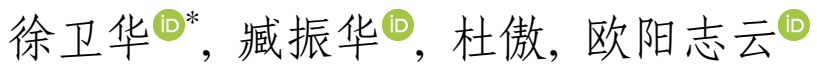

中国科学院生态环境研究中心城市与区域生态国家重点实验室, 北京 100085

徐卫华, 藏振华, 杜傲, 欧阳志云 (2021) 东北虎豹国家公园试点经验. 生物多样性, 29, 295-297. doi: 10.17520/biods.2021044.

Xu WH, Zang ZH, Du A, Ouyang ZY (2021) The experiences of Northeast China Tiger and Leopard National Park pilot. Biodiversity Science, 29, 295-297. doi: 10.17520/biods.2021044.

\section{The experiences of Northeast China Tiger and Leopard National Park pilot}

Weihua $\mathrm{Xu}^{(\mathbb{D} *}$, Zhenhua Zang ${ }^{(\mathbb{D})}$, Ao Du, Zhiyun Ouyang ${ }^{(\mathbb{D}}$

State Key Laboratory of Urban and Regional Ecology, Research Center for Eco-Environmental Sciences, Chinese Academy of Sciences, Beijing 100085

东北虎豹国家公园体制试点区位于吉林、黑龙 江两省交界的老爷岭南部区域, 跨吉林、黑龙江两 省, 与俄罗斯、朝鲜接壤, 试点区面积 1.46 万 $\mathrm{km}^{2}$, 其中 $69.4 \%$ 位于吉林省, 30.6\%位于黑龙江省(梁兵 宽等, 2020)。试点区的主要保护对象为温带针阔叶 混交林生态系统, 以及野生东北虎(Panthera tigris altaica)、东北豹( $P$. pardus orientalis) 为旗舰物种的 野生动植物及其栖息地。自2017年开展国家公园试 点以来，东北虎豹国家公园在创新中央垂管体制、 构建“天空地”一体化监测体系、开展跨境保护、宣 传国家公园理念等方面取得积极进展, 为推进国家 公园体制建设积累了重要经验。

\section{创新中央垂直管理、央地协同的体制机制}

目前国家公园体制试点形成了中央垂直管理、 中央与地方共同管理、地方管理3种管理模式, 东北 虎豹国家公园试点区是目前唯一由国家林业和草 原局(国家公园管理局)代表中央政府垂直管理的试 点区(藏振华等, 2020)。虎豹公园基本建立了 “管理 局-管理分局-基层保护站” 的三级垂直管理体系, 管理局以下成立 10 个管理分局, 分局以下设立国家 公园保护站。

同时，虎豹公园还是第一个在国家公园体制试
点基础上同步开展健全国家自然资源资产体制试 点的国家公园(张陕宁, 2018)。虎豹公园管理局联合 吉林、黑龙江两省各级有关行政主管部门，通过制 定移交清单, 交接档案资料, 明确与当地政府的事 权划分。这些权力清单包含林草、自然资源、水利、 农业农村、生态环保等部门, 涉及行政许可、行政 处罚、行政征收、行政强制、行政确认、行政裁决、 行政给付、行政奖励和其他行政权力等 9 类行政职 能1,561项，以实现对各类国有自然资源资产的统 一管理。

这种以东北虎豹国家公园管理局为核心、以中 央垂管为主线、以地方各级政府和部门为协同的管 理体制机制，为中央政府直接行使国家公园的全民 自然资源资产所有权体制奠定了坚实基础。

\section{2 构建 “天空地”一体化监测体系}

完善的监测体系是东北虎、东北豹等野生动植 物保护、自然资源管理的基础。试点区依托北京师 范大学等国内外高水平大学和科研机构, 成立了国 家林业和草原局东北虎豹监测与研究中心, 设立了 东北虎豹生物多样性国家野外科学观测研究站, 开 通了东北虎豹国家公园自然资源监测和管理系统。 该系统设置国家级、省级、区域和基础网络监测点 
四级平台, 并按照“统一规划、统一标准、统一制式、 统一平台、统一管理”的原则, 制定了《东北虎豹国 家公园自然资源监测体系建设技术指标》，确保监 测体系统一、规范、高效运行。

试点区采用全新的“互联网 + 生态”的信息 化、智能化管理模式, 通过建设基站、设置视频卡 口、布设红外相机等方式, 实现了园区范围内近万 平方公里的监测覆盖, 实时开展野生动物、人为活 动、自然资源和生态因子等30多个指标的监测。试 点区内的监测体系已获取了大量东北虎、东北豹、 梅花鹿(Cervus nippon)等野生动物活动影像以及自 然资源监测数据, 为保护巡护提供了大数据支撑 (王天明等, 2020)。同时, 各分局加强了常规监测, 按照标准网格化方法, 做到了巡护无死角、无盲区、 全覆盖, 持续开展 “清山清套” 等专项打击和监管行 动, 有效打击了违法行为, 保障了野生动物和森林 资源安全(陈雅如等, 2019)。

虎豹国家公园构建了国际先进的“天空地”一体 化自然资源监测和管理系统, 为“看得见虎豹、管得 住人”的目标实现提供有效保障, 为国家公园提高 自然资源资产监管能力、推动最严格保护实现路径 提供了示范(间颜等, 2021)。

\section{3 完善跨境保护合作机制}

虎豹国家公园是目前唯一地处国境边界的试 点区, 国家公园的主要保护对象东北虎、东北豹也 仅分布于中、俄边境狭窄的林区地带。为实现对东 北虎、豹的全面保护, 虎豹公园管理局与俄罗斯豹 地国家公园构建了跨国合作保护平台, 完善野生动 物保护的跨国合作机制。双方签署了《虎豹保护合 作谅解备忘录》，制定了2019-2021年联合行动计划, 明确在东北虎豹科学研究、生态监测、环境教育和 生态体验等领域开展跨境合作, 落实中俄两国元首 在莫斯科签署的《关于发展新时代全面战略协作伙 伴关系的联合声明》。目前完成了中俄边境 $200 \mathrm{~km}$ 的 虎豹跨境监测带、虎豹核心区和扩散区的监测安装 任务。

我国国境线长、邻国众多, 部分边境地区的地 理区位和生态价值重要, 国家代表性强, 随着国家 公园体制建设的深入, 将来会陆续在这些地区建立 多个国家公园。虎豹国家公园跨境保护合作机制的
经验可为将来建设边境国家公园提供积极借鉴。

\section{探索国家公园理念传播途径}

国家公园是开展自然教育、传播生态文明理念 的重要基地。虎豹公园管理局积极探索多种途径加 强国家公园科普宣教工作，引导社会广泛参与国家 公园建设，传播国家公园理念。首先，依托国内主 流媒体、自身官方网站和微信公众号“虎豹新观察” 等融媒体, 将虎文化元素紧密融入到宣传工作中, 通过开展“世界老虎日” “东北虎豹国家公园建设发 展论坛”等活动广泛宣传国家公园, 为东北虎豹国 家公园建设营造了浓厚舆论氛围。其次, 组织开展 生态旅游体验和自然教育，每年参与体验达 80 余万 人次。再次，建立健全志愿者服务机制，制定志愿 者管理办法，完善志愿者招募、注册、培训等制度， 吸引社会各界参与国家公园建设。最后, 广泛开展 交流，与俄罗斯、韩国等国家的自然保护地建立沟 通合作机制，与国际野生生物保护学会(WCS)、自 然资源保护协会(NRDC)等国际组织紧密合作开展 社区培训等活动, 推广对保护地友好的生产生活方 式，与国内多所高校、科研机构、保护地等紧密合 作，扩大了社会影响力。

试点区全方位、立体式宣传活动把生态文明建 设、国家公园体制建设、自然资源产权制度的理念 传达到了全社会，得到广泛认同与拥护，虎豹公园 成为了向世界传播生态文明理念、展示中国生物多 样性保护负责任大国形象的重要窗口。

东北虎豹国家公园试点取得了积极的生态成 效, 监测数据显示东北虎、东北豹的活动范围逐渐 扩大、种群数量稳定增长, 各类人为活动干扰不断 降低。作为目前唯一由中央政府直接管理、且同时 开展“两项试点”的国家公园，东北虎豹试点区的体 制改革具有重要的引领意义。东北虎豹国家公园的 试点实践, 为推进自然资源科学保护与合理利用、 全面深化国家公园建设提供了重要经验。

致谢: 感谢国家公园管理局办公室与东北虎豹国家 公园管理局提供支持，本文部分资料来源于《东北 虎豹国家公园试点评估报告》和《东北虎豹国家公 园试点评估验收报告》，在此向报告编写人员致谢。 


\section{ORCID}

徐卫华 (D) https://orcid.org/0000-0001-7622-7365

蔵振华 (D) https://orcid.org/0000-0002-6643-9468

欧阳志云 (iD https://orcid.org/0000-0003-0927-0499

\section{参考文献}

Chen YR, Han JK, Qin LN, Yang HC (2019) The problems and development approach of the Northeast Tiger and Leopard National Park System Pilot. Environmental Protection, 47(14), 61-65. (in Chinese) [陈雅如, 韩俊魁, 秦岭南, 杨 怀超 (2019) 东北虎豹国家公园体制试点面临的问题与 发展路径研究. 环境保护, 47(14), 61-65.]

Liang BK, Liu Y, Tang XP, Ban Y, Jiang YF, Kong Y, Li BB, Bai L (2020) Research on the planning of Amur Tiger and Amur Leopard National Park. Forest Resources Management, (6), 23-30. (in Chinese with English abstract) [梁兵宽, 刘洋, 唐小平, 班勇, 蒋亚芳, 孔颖, 李兵兵, 白玲 (2020) 东北虎豹国家公园规划研究. 林业资源管 理, (6), 23-30.]

Wang TM, Feng LM, Yang HT, Bao L, Wang HF, Ge JP (2020) An introduction to Long-term Tiger-Leopard Observation Network based on camera traps in Northeast China. Biodiversity Science, 28, 1059066. (in C hinese with English abstract) [王天明, 冯利民, 杨海涛, 鲍蕾, 王
红芳, 葛剑平 (2020) 东北虎豹生物多样性红外相机监 测平台概述. 生物多样性, 28, 1059-1066.]

Yan Y, Tang FL, Tian YC, Jin K (2021) On implementation path of the strictest conservation policies in National Park management. Biodiversity Science, 29, 123-128. (in Chinese with English abstract) [间颜, 唐芳林, 田勇臣, 金 崑 (2021) 国家公园最严格保护的实现路径. 生物多样 性, 29, 123-128.]

Zang ZH, Zhang D, Wang N, Du A, Kong LQ, Xu WH, Ouyang ZY (2020) Experiences, achievement, problems and recommendations of the first batch of China's National Park system pilots. Acta Ecologica Sinica, 40, 8839-8850. (in Chinese with English abstract) [㶓振华, 张多, 王楠, 杜傲, 孔令桥, 徐卫华, 欧阳志云 (2020) 中国首批国家公园体 制试点的经验与成效、问题与建议. 生态学报, 40, 8839-8850.]

Zhang SN (2018) Solid stability to promote two pilot projects of Northeast China Tiger and Leopard National Park. Forestry Construction, (5), 197-203. (in Chinese) [张陕宁 (2018) 扎实推进东北虎豹国家公园两项试点. 林业建设, (5), 197-203.]

(责任编委：马克平 责任编辑：周玉荣) 